\title{
Currículo e práticas pedagógicas - Uma análise sociológica de textos e contextos da educação em ciências
}

\author{
Vanda Alves \& Ana Maria Morais \\ Instituto de Educação da Universidade de Lisboa, Portugal
}

\begin{abstract}
Resumo
O estudo analisa em que medida a mensagem sociológica transmitida pela prática pedagógica de professores de Ciências Naturais representa uma recontextualização do Discurso Pedagógico Oficial veiculado no currículo de Ciências Naturais do $3^{\circ}$ Ciclo do Ensino Básico. Teoricamente, a investigação baseia-se em teorias das áreas da psicologia, da epistemolo-gia e da sociologia, destacando-se a teoria do discurso pedagógico de Bernstein. No estudo usa-se uma metodologia mista. Os resultados sugerem a existência de processos de transformação da mensagem dentro do Ministério da Educação, quando se passa dos princípios gerais do currículo para os princípios específicos do mesmo, no sentido do decréscimo da qualidade da educação científica. Discutem-se os resultados da análise do currículo quanto a características particulares estudadas: conhecimentos metacientíficos, competências e conhecimentos científicos, intradisciplinaridade e critérios de avaliação. Os resultados também mostram a ocorrência de uma diminuição da qualidade do processo de ensino-aprendizagem quando se passa do currículo para as práticas pedagógicas, evidente na ausência, pelas professoras, da posse de regras de reconhecimento e realização passiva e ativa para a maioria das características em estudo. Estes processos de transformação da mensagem são discutidos e exploram-se as suas consequências em termos de aprendizagem científica.
\end{abstract}

Palavras-chave

Educação científica; Currículo; Prática pedagógica; Recontextualização

\section{Introdução}

A reforma educativa do Ensino Básico, que foi implementada em 2001/2002, teve como objetivo unificar por temáticas e competências os três 
ciclos de ensino e como princípio orientador a gestão flexível do currículo consignada na Lei de Bases do Sistema Educativo Português, de 1986. A flexibilidade curricular tem como propósito a procura das respostas mais adequadas aos contextos e alunos reais com os quais os professores trabalham e assume que as escolas devem ter um maior poder de decisão no que concerne ao desenvolvimento e gestão das diversas componentes do currículo.

O currículo do Ensino Básico está expresso em dois documentos fundamentais: Competências Essenciais e Orientações Curriculares. O primeiro documento possui um carácter geral, referindo-se às competências que deverão ser desenvolvidas no nível de ensino em questão; o segundo documento, de cariz mais específico, pretende providenciar as orientações relativas a cada uma das disciplinas.

Embora os documentos curriculares devam ser os elementos orientadores das decisões pedagógicas dos professores e autores de recursos pedagógicos (caso dos manuais escolares e software educativo), a autonomia que Ihes foi possibilitada pelo contexto de gestão flexível cria um significativo espaço de recontextualização dos princípios contidos nesses documentos. Considerando que as práticas pedagógicas dos professores influenciam diretamente a aprendizagem dos alunos, reveste-se de grande importância a análise e problematização da direção e do grau dessa recontextualização.

O presente estudo faz parte de uma investigação mais abrangente (Alves, 2007), a qual se focou no contexto das Ciências Naturais para o $3^{\circ}$ Ciclo do Ensino Básico e onde se analisou a mensagem sociológica transmitida: (a) pelo Discurso Pedagógico Oficial (DPO) do Currículo de Ciências Naturais; (b) pelo Discurso Pedagógico de Reprodução (DPR) de software didático construído com base no currículo; e (c) pela prática pedagógica de professores de ciências. Foram, também, analisados os processos de recontextualização ocorridos entre os três níveis de análise (Figura 1). Este artigo foca-se, em particular, no seguinte problema: Em que medida a mensagem sociológica transmitida pela prática pedagógica de professores de Ciências Naturais representa uma recontextualização do Discurso Pedagógico Oficial? De acordo com este problema, estabeleceramse as seguintes questões de investigação: 1) Qual a mensagem sociológica 
presente no DPO?; 2) Qual a mensagem sociológica presente nas práticas pedagógicas dos professores de Ciências Naturais?; e 3) Qual o sentido e a extensão da recontextualização que os professores de Ciências Naturais fazem do DPO?

A análise do discurso pedagógico teve em consideração o que e 0 como da aprendizagem científica. No que diz respeito ao que, o estudo foi baseado no conhecimento metacientífico (construção da ciência), no conhecimento científico e nas competências científicas. No que concerne ao como, baseou-se nas relações entre discursos - relações entre conhecimentos científicos e metacientíficos e entre diferentes conhecimentos científicos - e nos critérios de avaliação inerentes à explicitação destas relações e dos conhecimentos e competências metacientíficos(as) e científicos(as) a serem focados/explorados. O nível de exigência conceptual foi outra importante dimensão em análise.

A seleção destas características esteve diretamente relacionada com os resultados de investigações prévias. No que respeita à importância de uma integração contextualizada da construção da ciência no processo de ensinoaprendizagem, vários estudos nesta área (por exemplo, McComas, Clough, \& Almazroa, 1998) mostraram que a educação científica deve conter uma perspetiva metacientífica, a qual, de acordo com Ziman (1984), se expressa em várias dimensões (filosófica, histórica, psicológica e sociológica interna e externa). Estudos anteriores (Domingos, 1989; Morais \& Neves, 2001; Morais, Neves, \& Pires, 2004) vieram sugerir que a promoção de um elevado nível de desenvolvimento científico implica uma prática pedagógica que, entre outros atributos, seja caracterizada por um elevado nível de exigência conceptual, pela existência de intradisciplinaridade e pela explicitação dos critérios de avaliação. Um elevado nível de exigência conceptual é também apontado por Vygotsky (1978), quando salienta a importância do desenvolvimento de processos mentais elevados, e é ainda baseado na estrutura hierárquica do conhecimento científico (Bernstein, 1999). Estas ideias suportam, igualmente, um elevado grau de intradisciplinaridade, o qual "pode ser alcançado quando se estabelecem relações fortes e complexas entre os temas organizadores e ainda quando se unifica a aprendizagem dos conhecimentos em torno de uma ideia estruturadora de grande abrangência e complexidade conceptual" (Neves \& Morais, 2006, p. 8). No que concerne ao grau de explicitação dos 
critérios de avaliação, a investigação tem mostrado que critérios de avaliação explícitos são o aspeto mais crucial para uma aprendizagem científica efetiva, particularmente nos casos de exigência conceptual elevada e no caso de alunos socialmente desfavorecidos (ex. Morais, Neves, \& Pires, 2004). Neste estudo, as características mencionadas serão, seguidamente, referidas como modelo teórico.

O modelo da Figura 1 contém as características e as relações que foram selecionadas para o estudo.

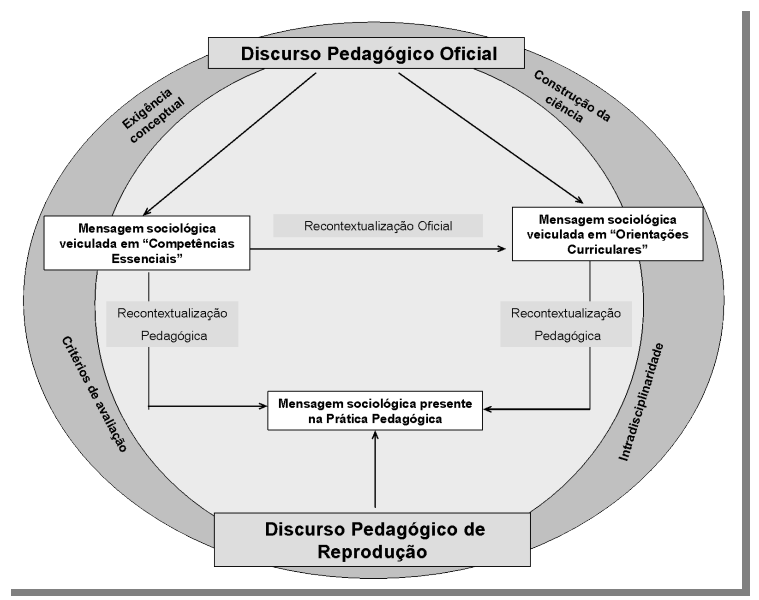

Figura 1 - Modelo de análise

\section{Enquadramento teórico}

O presente estudo é genericamente baseado em teorias das áreas da psicologia, da epistemologia e, fundamentalmente, da sociologia. Em termos sociológicos, a teoria do discurso pedagógico de Bernstein $(1990,2000)$ constituiu a principal base conceptual do estudo. Selecionou-se a teoria de Bernstein como quadro conceptual de referência pelo facto de esta teoria possuir um forte poder explicativo, pois é caracterizada por uma forte linguagem de descrição que permite analisar, descrever, comparar, diferenciar situações e acontecimentos. De acordo com Bernstein, e fazendo referência aos objetos deste estudo, o texto de qualquer currículo representa o Discurso 
Pedagógico Oficial (DPO) produzido no campo de recontextualização oficial (Ministério da Educação) e é resultado de múltiplas influências dos campos de Estado, controlo simbólico e económico, assim como de tendências internacionais. Na perspetiva sociológica desta investigação, a prática pedagógica dos professores traduz uma recontextualização do discurso pedagógico oficial (programa), recontextualização que, de acordo com o modelo do discurso pedagógico de Bernstein, é influenciada, em maior ou menor grau, pelos campos da economia e do controlo simbólico e será representativa do Discurso Pedagógico de Reprodução (DPR).

A implementação de determinada prática pedagógica requer que 0 professor possua uma orientação específica de codificação para o contexto dessa prática. A orientação específica de codificação (OEC) contém dois princípios: as regras de reconhecimento, que criam os meios necessários para a distinção entre contextos $e$, consequentemente, para $o$ reconhecimento da especificidade de determinado contexto; e as regras de realização, que criam os meios para a seleção dos significados adequados ao contexto (componente passiva) e para a produção do texto legítimo nesse contexto (componente ativa). $\mathrm{O}$ desempenho do sujeito, neste caso 0 desempenho do professor, requer também a posse de disposições socioafetivas favoráveis (motivações, aspirações, valores) para o contexto da prática pedagógica em causa. As regras de reconhecimento estão relacionadas com a classificação (C) que aprecia as relações de poder, isto é, o grau de manutenção das fronteiras entre categorias (sujeitos, discursos e espaços), no âmbito da dimensão organizacional da educação. A classificação assume valores fortes quando há uma nítida separação entre as categorias e assume valores fracos quando há um esbatimento das fronteiras entre essas categorias. As regras de realização estão relacionadas com o enquadramento (E) que aprecia as relações de controlo, ou seja, a comunicação entre sujeitos, no âmbito da dimensão interacional da educação. $O$ enquadramento é considerado forte quando a categoria superior tem o controlo na relação e é considerado fraco quando a categoria inferior tem alguma forma de controlo na mesma relação. Valores específicos de classificação e de enquadramento definem contextos específicos e, como tal, formas específicas de aquisição e de transmissão. 
No âmbito do enquadramento teórico descrito, as práticas pedagógicas dos professores podem ser analisadas como contextos de aprendizagem científica que geram textos, os quais representam determinados níveis do desempenho dos professores, ou seja, determinados níveis de orientação específica de codificação para a implementação de práticas pedagógicas com certas características sociológicas (Morais \& Neves, 2005).

Finalmente, é de referir que a Teoria de Bernstein (Bernstein, 1990, $1999,2000)$ constitui um vasto campo conceptual com poder explicativo que permite interpretar sociologicamente o fenómeno educativo a nível macroestrutural (Sociedade/sistema educativo) e a nível microinteracional (Escola/sala de aula). No âmbito do seu quadro conceptual, e de acordo com Morais (2002), torna-se possível estabelecer uma relação entre a linguagem interna de descrição, constituída por uma teoria ou conjunto de teorias, e a linguagem externa de descrição. Esta última é constituída por proposições e modelos derivados do confronto entre a linguagem interna de descrição e os dados empíricos. A linguagem externa de descrição é, portanto, o meio pelo qual a linguagem interna é ativada, funcionando como a interface entre os dados empíricos e os conceitos da teoria (Bernstein, 2000). Considera-se que o presente estudo poderá contribuir para o desenvolvimento de uma linguagem externa de descrição, baseada na relação dialética entre as proposições teóricas e os dados empíricos, uma vez que houve a construção de modelos e instrumentos conceptuais, assim como o desenvolvimento de metodologias fundamentadas no presente quadro teórico.

\section{Metodologia}

\section{Aspetos gerais}

Este estudo é interpretativo e situa-se no âmbito de uma metodologia mista, onde se combinam as abordagens quantitativas e qualitativas (Tashakkori \& Creswell, 2007; Morais \& Neves, 2010). A abordagem quantitativa foi usada quando, na construção dos instrumentos, se definiram categorias de análise com base em teorias e conceitos de áreas educacionais. A abordagem qualitativa foi usada na análise de textos, entrevistas e registos de observações em sala de aula, assim como no 
processo de redefinição de categorias. O sistema de categorias e indicadores resultou de uma relação dialética entre o teórico e o empírico.

Ao seguir uma metodologia mista, o estudo teve em consideração uma perspetiva teórica explícita, onde os dados empíricos foram analisados com base num forte quadro conceptual teórico. Seja de forma explícita ou não, todas as investigações são teoricamente guiadas e os princípios teóricos são essenciais para conferir coerência à recolha e análise dos dados (Bogdan \& Biklen, 1994). Segundo Burkhardt e Schoenfeld (2003), um bom modelo de investigação em educação deve conter, entre outras características, uma base teórica relativamente estável. Para estes autores, é fundamental que a investigação em educação contribua para o aparecimento de "teorias mais robustas e mais abrangentes e para a compreensão de que aspectos de que teorias se aplicam melhor em cada contexto" (p.10).

No que respeita à análise do currículo, enquanto o documento Competências Essenciais foi analisado na íntegra, a análise das Orientações Curriculares foi limitada ao subtema "O Organismo Humano em Equilíbrio", do tema "Viver melhor na Terra", o qual corresponde ao $9^{\circ}$ ano de escolaridade. A análise da prática pedagógica dos professores, ao nível de sala de aula, foi focada na unidade temática "Alimentação e Sistema Digestivo", que faz parte do referido subtema.

A seleção da amostra de professores foi limitada pelo uso, em sala de aula, das tecnologias de informação e comunicação, e a amostra foi composta por duas professoras: a professora Sofia e a professora Carla. A professora Sofia ensinava num colégio privado nos arredores de Lisboa e a professora Carla lecionava numa escola pública da zona litoral-centro de Portugal. De forma a analisar o currículo e a prática pedagógica das professoras, foram elaborados, pilotados e aplicados instrumentos de análise. Estes instrumentos foram baseados em modelos e instrumentos desenvolvidos em investigações anteriores (ex. Castro, 2006; Morais \& Neves, 2001; Morais, Neves, \& Afonso, 2005; Neves \& Morais, 2001a) mas constituem um passo em frente na investigação, ao alcançarem níveis mais elevados de conceptualização, abrangência e precisão.

Os instrumentos para análise do currículo e da prática pedagógica dos professores focaram-se em quatro características pedagógicas selecionadas para o estudo: construção da ciência, exigência conceptual, 
intradisciplinaridade e critérios de avaliação. Para a análise dos documentos curriculares, foram elaborados os seguintes instrumentos ${ }^{1}$ : dois para a construção da ciência ( 1 - Conhecimentos e competências; 2 - Complexidade do conhecimento metacientífico); dois para a intradisciplinaridade (3 Relações entre conhecimentos científicos e metacientíficos; 4 - Relações entre diferentes conhecimentos científicos); três para os critérios de avaliação (5 - Critérios de avaliação para o conhecimento metacientífico; 6 - Critérios de avaliação para as relações entre conhecimentos científicos e metacientíficos; 7 - Critérios de avaliação para as relações entre diferentes conhecimentos científicos). A exigência conceptual foi analisada através do uso do instrumento 4 e de dois outros instrumentos (8 - Complexidade das competências cognitivas científicas; 9 - Complexidade dos conhecimentos científicos).

O instrumento 1 continha uma lista de competências e de conhecimentos relativos à construção da ciência. Para os instrumentos $2,8 \mathrm{e}$ 9 usou-se uma escala de graus de crescente complexidade. Nos instrumentos para análise da intradisciplinaridade usou-se uma escala decrescente de graus de classificação $\left(\mathrm{C}^{++}, \mathrm{C}^{+}, \mathrm{C}^{-}, \mathrm{C}^{-}\right)$e nos instrumentos de análise dos critérios de avaliação usou-se uma escala decrescente de graus de enquadramento $\left(E^{++}, E^{+}, E^{-}, E^{--}\right)$. De forma a analisar o nível de exigência conceptual do conhecimento científico, foi concebido um índice compósito, o qual implicava a conjugação de três fatores: a intradisciplinaridade entre diferentes conhecimentos científicos, a complexidade das competências científicas e a complexidade dos conhecimentos científicos.

A prática pedagógica dos professores foi analisada em termos da sua orientação específica de codificação (OEC), ou seja, a sua posse (ou não) das regras de reconhecimento e de realização para o contexto específico da aprendizagem científica, no que concerne às mesmas características que foram usadas na análise do currículo: construção da ciência, exigência conceptual, intradisciplinaridade e critérios de avaliação. Para tal, foi elaborado, pilotado e aplicado um guião de uma entrevista semiestruturada e um instrumento para caracterização da prática pedagógica. A entrevista ${ }^{2}$ possibilitou a aquisição de dados acerca das regras de reconhecimento, realização passiva e realização ativa ao nível da argumentação e o instrumento para a caracterização da prática pedagógica ${ }^{3}$ permitiu a 
aquisição de dados sobre as regras de realização ativa ao nível da implementação. O nível de argumentação refere-se à capacidade de o professor explicar como atuaria na sua prática, quanto a uma determinada característica pedagógica, e o nível de implementação refere-se à sua capacidade de, efetivamente, atuar em conformidade ${ }^{4}$.

\section{Análise do currículo}

De forma a realizar a análise dos dois documentos curriculares, foram criadas unidades de análise, as quais foram organizadas em quatro secções: Conhecimentos, Finalidades, Orientações Metodológicas e Avaliação. Cada unidade de análise - excerto do texto curricular com determinado valor semântico - foi analisada através da utilização dos vários instrumentos. Para uma melhor compreensão da análise efetuada, apresenta-se, seguidamente, para duas das características em estudo - Intradisciplinaridade entre diferentes conhecimentos científicos e Complexidade dos conhecimentos científicos -, um excerto do respetivo instrumento (Tabelas I e II) e algumas unidades de análise classificadas de acordo com as escalas do instrumento.

Tabela I - Excerto do instrumento para caracterização das relações intradisciplinares entre diferentes conhecimentos científicos

\begin{tabular}{|c|c|c|c|}
\hline $\mathrm{c}^{++}$ & $\mathrm{c}^{+}$ & $c^{-}$ & $c^{--}$ \\
\hline $\begin{array}{l}\text { Contemplam a relação } \\
\text { entre conhecimentos de } \\
\text { ordem simples dentro do } \\
\text { mesmo tema. [1] } \\
\text { Ou }\end{array}$ & $\begin{array}{l}\text { Contemplam a relação } \\
\text { entre conhecimentos de } \\
\text { ordem simples de temas } \\
\text { diferentes. [1] } \\
\text { Ou }\end{array}$ & $\begin{array}{l}\text { Contemplam a relação } \\
\text { entre conhecimentos de } \\
\text { ordem complexa, ou entre } \\
\text { estes e conhecimentos de } \\
\text { ordem simples, dentro do }\end{array}$ & $\begin{array}{l}\text { Contemplam a relação } \\
\text { entre conhecimentos de } \\
\text { ordem complexa, ou entre } \\
\text { estes e conhecimentos de } \\
\text { ordem simples, de temas }\end{array}$ \\
\hline $\begin{array}{l}\text { É omisso conhecimento } \\
\text { científico indispensável à } \\
\text { compreensão da relação } \\
\text { entre conhecimentos } \\
\text { dentro do mesmo tema. [2] }\end{array}$ & $\begin{array}{l}\text { É omisso conhecimento } \\
\text { científico indispensável à } \\
\text { compreensão da relação } \\
\text { entre conhecimentos de } \\
\text { temas diferentes. [2] }\end{array}$ & & \\
\hline \multicolumn{4}{|c|}{$\begin{array}{l}\text { "Os alunos devem ficar a conhecer aspetos morfológicos e fisiológicos básicos dos sistemas referidos de modo } \\
\text { a compreenderem a importância da circulaçäo sanguínea, respiraçăo pulmonar, digestão, absorção } \\
\text { eliminaçăo de substâncias produzidas no organismo, compreendendo o funcionamento dos sistemas de modo } \\
\text { integrado" (Orientaçôes Curriculares, Seç̧âo Finalidades) - Grau C } C^{+}[2]\end{array}$} \\
\hline \multicolumn{4}{|c|}{$\begin{array}{l}\text { "Mobilizaçäo e utilizaçäo de saberes tecnológicos - tratamento da água: processos físicos e químicos, casos } \\
\text { especiais de tratamento de água (como em hemodiálise), transporte de água, mecanismos de rentabilizaçäo } \\
\text { em casa, na agricultura, na jardinagem e na indústria" (Competências Essenciais, Seç̧ão Finalidades) - Grau } \\
\text { C. }\end{array}$} \\
\hline
\end{tabular}


A primeira unidade parece valorizar a intradisciplinaridade, mas a omissão do conceito de homeostasia no currículo limita essa possível intradisciplinaridade. A segunda unidade contém conhecimentos de ordem complexa (ex. processos físicos e químicos do tratamento de água) relacionados com conhecimentos de ordem simples (ex. transporte de água), dentro do mesmo tema.

\section{Tabela II - Excerto do instrumento que caracteriza a complexidade dos} conhecimentos científicos 5

\begin{tabular}{|c|c|c|}
\hline Grau 1 & Grau 2 & Grau 3 \\
\hline $\begin{array}{l}\text { Os conhecimentos } \\
\text { cientificos referem-se a } \\
\text { factos generalizados e/ou a } \\
\text { conceitos simples, com um } \\
\text { baixo nivel de abstraçāa } \\
\text { (conceitos de } 1^{\mathrm{a}} \text { ordem). }\end{array}$ & $\begin{array}{l}\text { Os conhecimentos } \\
\text { cientificos referem-se a } \\
\text { conceitos complexos, com } \\
\text { um nivel de abstracaão } \\
\text { superior ao dos conceitos } \\
\text { simples e formados por } \\
\text { atributos definidores não } \\
\text { percetiveis (conceitos de } 2^{\mathrm{a}} \\
\text { ordem). }\end{array}$ & $\begin{array}{l}\text { Os } \\
\text { conhecimentos } \\
\text { centificos referem-se a } \\
\text { emas unificadores, } \\
\text { envolvendo um nivel de } \\
\text { abstraçáo muito elevado } \\
\text { (conceitos de } 3^{\mathrm{a}} \text { ordem). }\end{array}$ \\
\hline
\end{tabular}

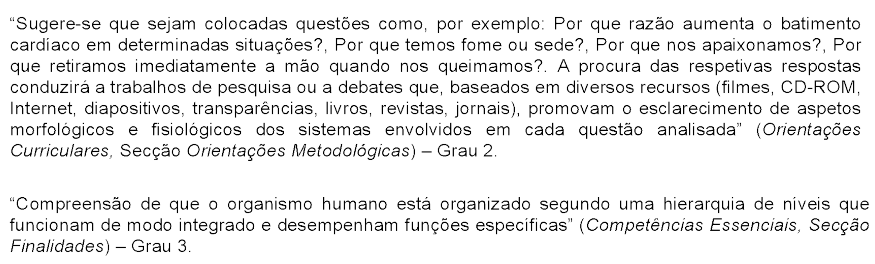

"Compreensão de que o organismo humano está organizado segundo uma hierarquia de niveis que funcionam de modo integrado e desempenham funçöes especificas" (Competências Essenciais, Seç̧ão Finalidades) - Grau 3 .

A primeira unidade envolve conceitos de segunda ordem, visto que a compreensão dos mesmos pressupõe a compreensão de conceitos de primeira ordem. A segunda unidade envolve conceitos de terceira ordem referentes a temas unificadores, neste caso generalizações acerca do corpo humano.

\section{Análise da OEC das professoras - Entrevista}

Para cada uma das características pedagógicas em análise, o guião da entrevista seguia os mesmos princípios. Inicialmente (Questão 1), solicitavase ao professor que selecionasse uma de três opções (sendo que uma das opções continha a característica pedagógica que a investigação tinha mostrado como sendo mais favorável à aprendizagem científica), de forma a 
se obter os primeiros dados referentes às regras de reconhecimento. A entrevista prosseguia com a realização de duas questões relacionadas com a questão 1 , ou seja, solicitava-se que o professor fornecesse as razões/argumentos para a opção que havia selecionado (Questão 2) e que apresenta-se justificações para que determinada opção fosse a considerada mais próxima do modelo teórico em causa (Questão 3). Estas respostas permitiriam obter dados relativos à posse (ou não) das regras de realização passiva, assim como resolver ambiguidades ou decisões pendentes quanto à posse (ou não) das regras de reconhecimento. Uma última questão (Questão 4) focava a forma de atuação, em sala de aula, no que concerne a cada uma das características pedagógicas em estudo e permitia a aquisição de dados quanto à posse (ou não) de regras de realização ativa ao nível da argumentação (ver Figura 2).

Os excertos da entrevista que se seguem dizem respeito à característica Critérios de Avaliação.

Questão 1: O sucesso e o insucesso na aprendizagem científica estão relacionados com várias causas. Das seguintes situações, em contexto de sala de aula, selecione aquela com que mais se identifica.

1) Ao abordar um conteúdo científico ou metacientífico, o professor fornece explicações pormenorizadas, mas não realiza momentos de síntese, deixando essa tarefa ao critério dos alunos, respeitando a individualidade dos mesmos.

2) Ao abordar um conteúdo científico ou metacientífico, o professor fornece explicações pormenorizadas e realiza, sempre que oportuno, momentos de síntese, de modo a explicitar os aspetos essenciais das atividades.

3) Ao abordar um conteúdo científico ou metacientífico, o professor fornece explicações pormenorizadas e realiza, apenas no final da unidade temática, um momento de síntese de modo a explicitar a ideia geral da mesma.

Questão 2: Por que razão escolheu a opção 1 (ou 2 ou 3)?

Se o professor selecionou a opção 1 na Questão 1, fornecer o excerto seguinte. Se tal não tiver sido o caso, a entrevista prossegue para a Questão 3. 
"Os critérios de avaliação constituem uma característica crucial da prática pedagógica. Quando os critérios de avaliação são explícitos, tal significa que o professor deixa claro, para os seus alunos, qual é o texto adequado a ser produzido, em determinado momento, como resultado da aprendizagem" (Morais, 2002).

Após a análise deste excerto sente a necessidade de alterar a escolha feita na Questão 1?

Questão 3: Para as perspetivas actuais do ensino das ciências, a opção mais aceite é a 2 (pode-se facultar essa opção ao professor para que ele a leia novamente, se necessário).

Qual a justificação que encontra para este facto?

Questão 4: Costuma ter a preocupação de, nas suas aulas, dinamizar um processo de ensino-aprendizagem em que clarifica o texto correto que quer que os alunos aprendam ou que produzam?

No caso de a resposta ser afirmativa, perguntar: Como é que faz? É capaz de exemplificar?

No caso de a resposta ser negativa, perguntar: Como é que faria para explicitar, claramente, nas suas aulas, aquilo que pretende que os alunos aprendam ou que produzam, por exemplo, num dado trabalho?

\section{Análise da OEC das professoras - Observação na sala de aula}

De forma a caracterizar a prática pedagógica dos professores, em termos das suas regras de realização ativa ao nível da implementação, as suas aulas foram observadas, gravadas em registo áudio e transcritas. $O$ instrumento usado para esta caracterização contém, para cada uma das características em estudo, vários indicadores e, para cada indicador, vários descritivos que correspondem aos graus das escalas elaboradas, em termos da natureza da característica em questão.

A Tabela III mostra um excerto do instrumento referente à característica Complexidade das competências cognitivas científicas, para o indicador "Exploração/discussão dos temas em estudo"6. Segue-se um 
excerto de um caso de interação na sala de aula que ilustra um dos graus da escala do instrumento.

Tabela III - Excerto do instrumento referente à complexidade das competências cognitivas científicas 7

\begin{tabular}{|c|c|c|c|}
\hline $\begin{array}{c}\text { Grau } 1 \\
\text { (CS) }\end{array}$ & $\begin{array}{c}\text { Grau } 2 \\
\left(\mathrm{CS}^{+}\right)\end{array}$ & $\begin{array}{l}\text { Grau 3 } \\
\left(\mathrm{CC}^{-}\right)\end{array}$ & $\begin{array}{c}\text { Grau } 4 \\
\left(\mathrm{CC}^{+}\right)\end{array}$ \\
\hline 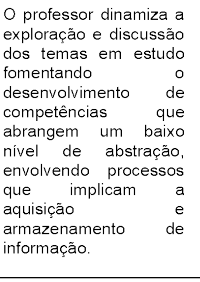 & $\begin{array}{l}\text { O professor dinamiza a } \\
\text { exploraçăo e discussão dos } \\
\text { temas em estudo } \\
\text { fomentandor } \quad \text { on } \\
\text { desenvolvimento de } \\
\text { competências que envolvem } \\
\text { um nivel de abstração } \\
\text { superior ao das CS, coma a } \\
\text { compreensão ao nivel da } \\
\text { translaçăa. }\end{array}$ & 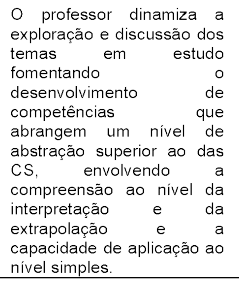 & $\begin{array}{l}\text { O professor dinamiza a } \\
\text { exploração e discussão dos } \\
\text { temas em estudo } \\
\text { fomentando } \\
\text { desenvolvimento de de } \\
\text { competências } \\
\text { abrangem um nivel due } \\
\text { abstração muito elevado, } \\
\text { envolvendo a capacidade } \\
\text { de aplicação a um nivel } \\
\text { elevado, bem como as } \\
\text { capacidades de análise, } \\
\text { sintese eavaliação. }\end{array}$ \\
\hline $\begin{array}{l}\text { [A professora e os } \\
\text { enzimas na digestä } \\
\text { P - [...] que tubo de } \\
\text { A - O tubo de ensai } \\
\text { P - O tubo de ensa } \\
\text { ácido clorídrico? Qu } \\
\text { A - Ácido. } \\
\text { P - Ácido, näo é? E } \\
\text { A - As proteinas! } \\
\text { P - Proteinas! Vame }\end{array}$ & $\begin{array}{l}\text { lunos discutiam os resultac } \\
\text { com proteínas. } \\
\text { com proteínas! Então, isso } \\
\text { é o pH do estômago? } \\
\text { täo, isso significa que a peps } \\
\text { agora olhar para a tina D [. }\end{array}$ & $\begin{array}{l}\text { C? } \\
\text { gnifica que a pepsina e o } \\
\text { quebra... } \\
\text { - Grau } 3\end{array}$ & $\begin{array}{l}\text { tal sobre a ação das } \\
\text { o clorídrico... Porquê o }\end{array}$ \\
\hline
\end{tabular}

Os estudantes interpretam os resultados, inferindo relações simples entre as características das enzimas e a sua ação, em diferentes situações.

A posse (ou não) de regras de realização ativa ao nível da implementação foi analisada através da aplicação do instrumento de caracterização da prática pedagógica, tendo-se determinado uma escala para medir os resultados obtidos, onde o valor de $50 \%$ foi definido como valor de referência. Exemplificando para o caso dos Critérios de avaliação: consideraram-se os critérios de avaliação explícitos (situação concordante com o modelo teórico) quando a frequência de unidades de análise classificadas com os graus $\mathrm{E}^{++}$ou $\mathrm{E}^{+}$era superior a $50 \%$. Este procedimento permitiu ainda a clarificação de eventuais situações ambíguas que haviam ficado pendentes na entrevista (ex.: dúvida quanto à posse de regras de realização ativa ao nível da argumentação). Finalizando, é importante referir que os dados obtidos quanto às regras de realização ativa ao nível da 
argumentação e implementação possibilitaram clarificar situações ambíguas quanto à posse (ou não) das regras de realização passiva.

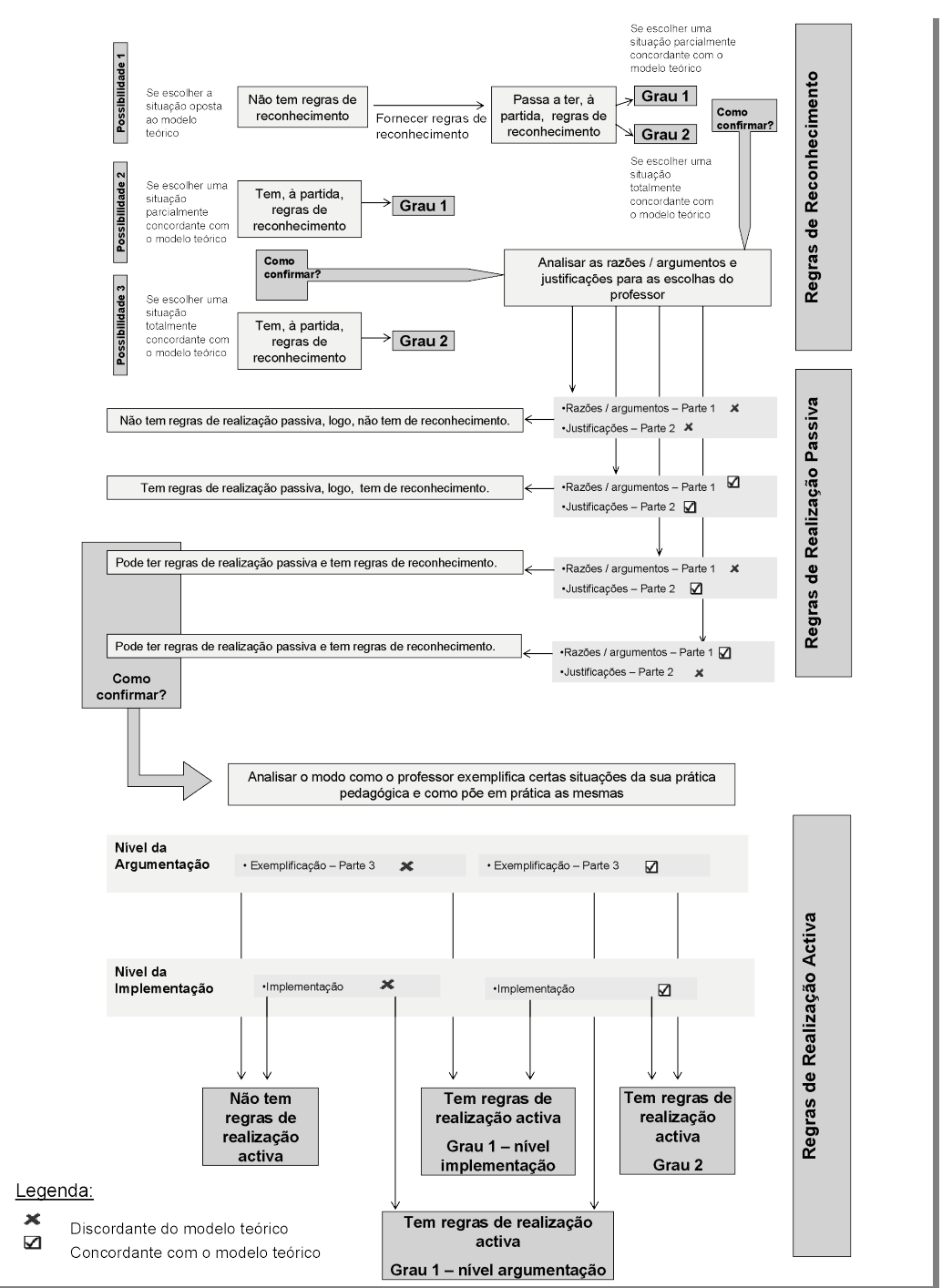

Figura 2 - Modelo de análise da orientação específica de codificação dos professores 
A Figura 2 representa o modelo de análise da OEC dos professores, o qual permite uma sistematização dos dados obtidos aquando da entrevista (no que diz respeito às regras de reconhecimento, regras de realização passiva e regras de realização ativa ao nível da argumentação) e aquando da aplicação do instrumento de caracterização da prática pedagógica (relativo às regras de realização ativa ao nível da implementação). A aplicação completa deste modelo só se verifica, efetivamente, quando se analisam todos os níveis em estudo.

A partir da análise dos dados obtidos através das entrevistas e da observação em sala de aula, verificou-se que podiam ocorrer as situações que se seguem.

A - Relativamente à escolha da opção com que a professora mais se identificava, de entre as três apresentadas:

Possibilidade 1. Quando seleciona a opção discordante do modelo teórico, a professora mostra não possuir regras de reconhecimento. Nesta situação, a entrevista prosseguiria no sentido de fornecer à entrevistada as regras de reconhecimento. Posteriormente, poder-se-ia observar uma das situações seguintes: se a professora, ao escolher novamente a opção com que mais se identificava, escolhesse a situação parcialmente de acordo com o modelo teórico, a professora passaria a ter, à partida, regras de reconhecimento Grau 1; se a professora, ao escolher novamente a opção com que mais se identificava, escolhesse a situação totalmente de acordo com o modelo teórico, a professora passaria a ter, à partida, regras de reconhecimento Grau 2.

Possibilidade 2. Quando seleciona a situação parcialmente de acordo com o modelo teórico, a professora manifesta possuir, à partida, regras de reconhecimento Grau 1. Para o confirmar, há que analisar as razões/argumentos (Parte 1) e as justificações (Parte 2) que fundamentam a opção escolhida e que explicam o motivo pelo qual determinada opção é considerada a mais aceite pelas perspetivas atuais do ensino das ciências, respetivamente.

Possibilidade 3. Quando seleciona a situação totalmente de acordo com o modelo teórico, a professora manifesta possuir, à partida, regras de reconhecimento Grau 2. Para o confirmar, há que analisar as razões/argumentos (Parte 1) e as justificações (Parte 2) que fundamentam a opção escolhida e que explicam o motivo pelo qual determinada opção é considerada a mais aceite pelas perspetivas atuais do ensino das ciências, respetivamente. 
B - Relativamente às razões/argumentos apresentadas/os pelas professoras para a escolha de determinada opção e às justificações apresentadas para que certa opção seja a considerada mais aceite pelas perspetivas atuais do ensino das ciências:

Possibilidade 1. Caso a professora não apresente razões/argumentos nem justificações concordantes com o modelo teórico, tal significa que a professora não tem regras de realização passiva para o contexto em causa. Perante este novo dado já é possível tirar as dúvidas relativamente à eventual posse, ou não, de regras de reconhecimento, nos casos em que essa posse não podia ser, determinantemente, tida como certa. Nesses casos, quando a professora não apresenta explicações em nenhuma das partes ( 1 e 2) concordantes com o modelo teórico, pode-se concluir que não tem regras de realização passiva e também não tem regras de reconhecimento.

Possibilidade 2. Caso a professora apresente razões/argumentos e ainda as justificações de acordo com o modelo teórico, tal significa que a professora tem regras de realização passiva para o contexto em causa. Perante este facto, pode-se concluir que a professora também possui regras de reconhecimento para a situação em questão.

Possibilidade 3. Caso a professora não apresente razões/argumentos, mas, pelo contrário, justifique de acordo com o modelo teórico, ou vice-versa ${ }^{8}$, também se podem esclarecer as dúvidas pendentes relativamente à posse das regras de reconhecimento e concluir que a professora as possui. No entanto, como apenas uma das partes estava correta, conclui-se que a professora pode possuir, ou não, regras de realização passiva. Para esclarecer as dúvidas pendentes, há que analisar o modo como o professor exemplifica certas situações da sua prática pedagógica e, eventualmente, caso as dúvidas subsistam, como põe em prática as mesmas.

C - Relativamente ao modo como o professor exemplifica certas situações da sua prática pedagógica e como as põe em prática:

C1 - Nível da argumentação, o qual pressupõe a compreensão da prática pedagógica:

Possibilidade 1A. No caso em que a professora exemplifica o modo como implementaria determinada prática pedagógica de forma discordante do modelo teórico, pode-se concluir que a professora não possui regras de realização ativa ao nível da argumentação. Caso esta situação ocorra, já é possível tirar ilações quanto à eventualidade de a professora ter regras de realização passiva para o 
contexto em causa, nos casos em que subsistiram ambiguidades: quando não há regras de realização ativa ao nível da argumentação, não há regras de realização passiva.

Possibilidade 1B. No caso em que a professora exemplifica o modo como implementaria determinada prática pedagógica de forma concordante com 0 modelo teórico, pode-se concluir que a professora possui regras de realização ativa ao nível da argumentação. Caso esta situação ocorra, já é possível tirar ilações, nos casos em que existiam dúvidas, quanto à eventualidade de a professora ter regras de realização passiva para o contexto em causa: quando há regras de realização ativa ao nível da argumentação, há regras de realização passiva.

C2 - Nível da implementação:

Possibilidade 2A. No caso em que a professora implementa uma prática pedagógica com características diferentes das do modelo teórico, pode-se concluir que a professora não possui regras de realização ativa ao nível da implementação. Quando as possibilidades $1 \mathrm{~A}$ e $2 \mathrm{~A}$ se verificam em simultaneidade na prática pedagógica da professora, podemos concluir que a professora não tem regras de realização ativa. Quando as possibilidades $1 \mathrm{~B}$ e 2A existem simultaneamente na mesma prática pedagógica, pode-se concluir que a professora possui regras de realização ativa Grau 1 - nível da argumentação.

Possibilidade 2B. No caso em que a professora implementa uma prática pedagógica com as mesmas características do modelo teórico, pode-se concluir que a professora possui regras de realização ativa ao nível da implementação. Quando as possibilidades 1A e 2B existem simultaneamente na mesma prática pedagógica, pode-se concluir que a professora possui regras de realização ativa Grau 1 - nível da implementação. Quando as possibilidades 1B e 2B existem simultaneamente na prática pedagógica da professora, podese concluir que a professora possui regras de realização ativa Grau 2 - nível da argumentação e da implementação.

De forma a ilustrar a aplicação do modelo, seguem-se exemplos de respostas dadas na entrevista por uma das professoras e sua interpretação em termos de regras de reconhecimento, de realização passiva e de realização ativa ao nível da argumentação, para a característica Critérios de avaliação. 
A professora começou por selecionar a opção totalmente concordante com o modelo teórico. Assim, a professora manifestou que, à partida, possuía regras de reconhecimento Grau 2 (Possibilidade A.3).

No que é referente às razões/argumentos (Parte 1) defendidos pela professora, constatou-se que ela valorizava os momentos de síntese como uma forma de tornar mais explícito o texto legítimo que pretendia que os alunos aprendessem. Além disso, a professora defendeu a necessidade de haver um fio condutor na lecionação dos temas que permita aos alunos compreender os fenómenos científicos de forma significativa. Pelo exposto, considera-se que as razões/argumentos (Parte 1) apresentadas/os são concordantes com o modelo teórico.

Excerto: " (...) Estes momentos de síntese, em determinados pontos, permitemme ter o feedback, se realmente eles estão a seguir, a acompanhar, ou não. Se deixamos para o final da unidade, um conteúdo, qualquer coisa que eles não entenderam bem, pode impedir a aprendizagem da fase seguinte. Para mim, o ideal é ser sempre esta" [refere-se à opção que escolheu] (Professora Carla, entrevista).

No que concerne às justificações (Parte 2), a professora não apresentou de forma clara a importância que representa, para um processo de ensino-aprendizagem efetivo e significativo, a realização das sínteses e de outras estratégias de clarificação do texto legítimo que os alunos devem aprender. Contudo, como na Parte 1 a professora respondeu de forma concordante com o modelo teórico, considerou-se que as justificações (Parte 2) eram parcialmente concordantes com o modelo teórico, carecendo de clarificação aquando da análise das regras de realização ativa ao nível da argumentação (Possibilidade B.3).

Excerto: "(...) e nós partimos do pressuposto que tudo isto tem um fio condutor, que tudo isto é uma construção, então (...) por exemplo, eu na casa não posso começar o telhado se não souber que o resto está muito bem sustentado, não é? Eu penso que ao nível da teoria é a mesma coisa... (...) Porque se falhou ali uma parte, como é que depois se vai construir em cima daquilo que não é seguro?" (Professora Carla, entrevista).

No que diz respeito ao modo como a professora exemplificou a forma de realizar sínteses e de clarificar o texto que os alunos deverão aprender, considerou-se que ela tinha algumas dificuldades em verbalizar o modo como executava tais procedimentos, tendo salientado apenas a realização dos 
mapas de conceitos. Contudo, salientou a importância de se realizar intradisciplinaridade, o que é também uma forma de clarificar o texto legítimo da aprendizagem em ciências. Considerou-se, assim, que a professora possuía regras de realização ativa ao nível da argumentação (Possibilidade 1B).

Excerto: "(...) dentro de algum ponto em que eu acho que é importante irmos parando - serem sempre eles a ir fazendo, claro, com a minha ajuda; com a construção dos ditos mapas de conceitos, por exemplo (...) no caso dos aparelhos, eles ligam o órgão aos processos físicos e químicos que acontecem aqui e ali, pronto, tentar fazer essa ligação para ver se eles conseguem fazer, ou não" (Professora Carla, entrevista).

Perante os dados recolhidos para a posse das regras de reconhecimento, de realização passiva e de realização ativa ao nível da argumentação, verificou-se que a professora tinha regras de reconhecimento grau 2, regras de realização passiva e regras de realização ativa ao nível da argumentação (grau 1). A análise dos dados relacionados com a posse de regras de realização ativa ao nível da implementação mostrou, no caso da mesma professora, que a frequência de unidades de análise classificadas com os graus $\mathrm{E}^{++}$e $\mathrm{E}^{+}$era inferior a $50 \%$, o que sugeriu que ela não possuía regras de realização ativa ao nível da implementação.

\section{Análise dos resultados}

\section{Análise do Currículo}

Os resultados da análise do currículo, no que concerne às características pedagógicas relacionadas com o que do DPO conhecimentos metacientíficos (construção da ciência) e competências e conhecimentos científicos - estão representados, resumidamente, no gráfico da Figura 3.

Os resultados representam a frequência de unidades de análise (UA) do currículo - Competências Essenciais (CE) e Orientações Curriculares (OC) -, classificadas de acordo com cada uma das escalas (de níveis crescentes de complexidade) dos respetivos instrumentos de análise. Para a análise do gráfico deve-se ter em consideração que os conhecimentos metacientíficos e as competências científicas foram avaliados numa escala de 4 graus e que os conhecimentos científicos foram avaliados numa escala de 3 graus. 


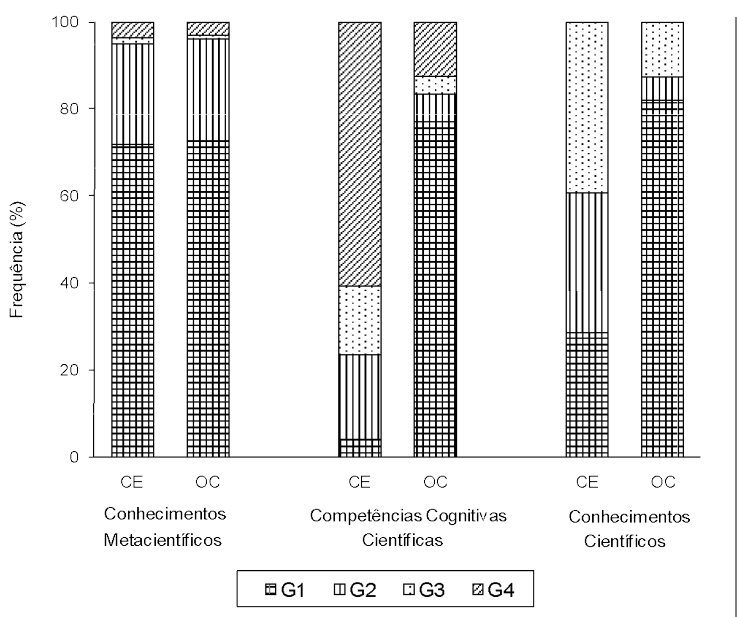

Figura 3 - O que do DPO: Complexidade dos conhecimentos metacientíficos, das competências cognitivas científicas e dos conhecimentos científicos

A análise do DPO do currículo, quando se consideram os dois documentos oficiais (Competências Essenciais e Orientações Curriculares), mostra que o nível de complexidade dos conhecimentos metacientíficos é baixo $(71,7 \%$ das UA das CE e $72,5 \%$ das UA das OC foram classificadas com o nível mais baixo da escala). O nível de complexidade dos conhecimentos científicos e das competências cognitivas é, no total, relativamente mais elevado do que o nível de complexidade do domínio metacientífico; contudo, segue um padrão que depende da mensagem contida em cada um dos documentos curriculares. De facto, e no que diz respeito às competências cognitivas, enquanto as Competências Essenciais contêm 60,8\% de UA com o nível mais elevado de complexidade e apenas 3,9\% de UA com o nível mais baixo, as Orientações Curriculares contêm apenas 12,5\% das UA com o nível de complexidade mais elevado e $77,1 \%$ das UA com o nível mais baixo de complexidade. No que concerne à complexidade dos conhecimentos científicos, verifica-se, claramente, que as Competências Essenciais apresentam níveis mais elevados de complexidade (39\% das UA foram classificadas com grau 3) do que as Orientações Curriculares (apenas 12,8\% as UA registaram uma classificação de grau 3). Neste último documento, a 
grande maioria das UA foi classificada com o grau 1, ou seja, conceitos de primeira ordem. Esta discrepância veio apoiar estudos prévios (Neves \& Morais, 2001a, 2006), os quais dão visibilidade aos processos de recontextualização existentes entre documentos produzidos no campo de recontextualização oficial ${ }^{9}$.

A Figura 4 representa, de forma resumida, os resultados da análise do currículo quanto às características pedagógicas relacionadas com o como do DPO - relações intradisciplinares entre conhecimentos científicos e metacientíficos e relações intradisciplinares entre diferentes conhecimentos científicos. Os resultados representam, tal como referido, a frequência de unidades de análise do currículo (Competências Essenciais e Orientações Curriculares) classificadas de acordo com cada um dos quatro graus das escalas (níveis crescentes dos valores de classificação) dos respetivos instrumentos de análise.

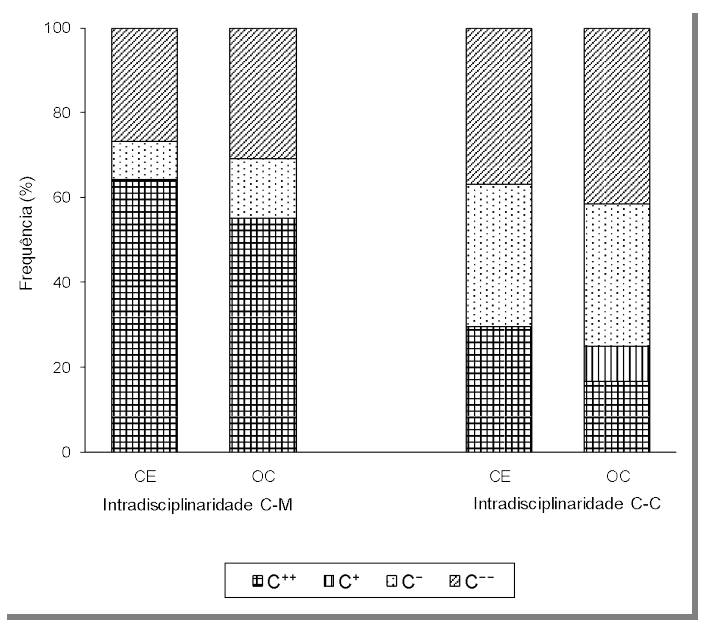

Figura 4 - 0 como do DPO: Relações intradisciplinares entre conhecimentos científicos e metacientíficos (Intradisciplinaridade C-M) e relações intradisciplinares entre diferentes conhecimentos científicos (Intradisciplinaridade C-C) 
Os resultados sugerem relações intradisciplinares, entre conhecimentos científicos e metacientíficos, muito fracas, em ambos os documentos (64,3\% das UA das Competências Essenciais e 55,2\% das UA das Orientações Curriculares foram classificadas com valores de $\mathrm{C}^{++}$). As relações intradisciplinares entre diferentes conhecimentos científicos são um pouco menos fracas (apenas $29,6 \%$ das UA das Competências Essenciais e $16,7 \%$ das UA das Orientações Curriculares foram classificadas com valores de $\mathrm{C}^{++}$), mas, no entanto, são ainda insuficientes para o alcance de níveis elevados de literacia científica.

Quanto à outra característica relacionada com o como do DPO Critérios de avaliação no domínio da relação transmissor-aquisidor (grau de explicitação das relações intradisciplinares e das competências e dos conhecimentos científicos e metacientíficos) -, os resultados mostram que 0 currículo é caracterizado por um grau de explicitação muito baixo, ou seja, as diretrizes para o texto a ser transmitido/adquirido são, predominantemente, subjetivas e pouco claras, especialmente no caso das Orientações Curriculares. Todas as unidades de análise foram classificadas com $\mathrm{E}^{-}$e $\mathrm{E}^{--}$ em ambos os documentos curriculares e em todas as dimensões de análise dos critérios de avaliação.

\section{Análise da prática pedagógica das professoras}

A Tabela IV apresenta uma síntese dos resultados (em termos da orientação específica de codificação) da análise das práticas pedagógicas das professoras.

Os resultados sugerem que a professora Sofia não possui regras de reconhecimento, regras de realização passiva e regras de realização ativa quer ao nível da argumentação quer ao nível da implementação, isto é, a sua orientação específica de codificação é, para todas as características pedagógicas em estudo, muito limitada. A professora Sofia foi incapaz de reconhecer a especificidade do contexto relativo a cada uma das características e de selecionar o texto legítimo que deveria produzir nesse contexto. Não mostrou ainda capacidade para apresentar as razões/argumentos/justificações que fundamentariam esse texto. Não soube também dizer como faria para implementar uma prática pedagógica com as 
características do modelo teórico do estudo, e foi ainda incapaz de implementar essa prática em sala de aula.

Tabela IV - Resultados da orientação específica de codificação das professoras

\begin{tabular}{|c|c|c|c|c|c|c|c|}
\hline \multirow{2}{*}{\multicolumn{3}{|c|}{$\begin{array}{c}\text { Caracteristica da Aprendizagem / } \\
\text { Professor }\end{array}$}} & \multirow{3}{*}{$\begin{array}{c}\begin{array}{c}\text { Regras de } \\
\text { Reconhecimento }\end{array} \\
x\end{array}$} & \multirow{3}{*}{\begin{tabular}{|c|}
$\begin{array}{c}\text { Regras de } \\
\text { Realização } \\
\text { Passiva }\end{array}$ \\
$x$ \\
\end{tabular}} & \multicolumn{3}{|c|}{ Regras de Realização Activa } \\
\hline & & & & & \multirow{2}{*}{$\begin{array}{c}\text { Argumentação } \\
\mathbf{x}\end{array}$} & \multirow{2}{*}{$\frac{\text { Implementação }}{x}$} & \multirow{2}{*}{\begin{tabular}{|c|}
$\begin{array}{c}\text { Caracterização } \\
\text { Total }\end{array}$ \\
$x$ \\
\end{tabular}} \\
\hline \multirow{2}{*}{\multicolumn{2}{|c|}{$\begin{array}{l}\text { Conhecimentos } \\
\text { Metacientificos }\end{array}$}} & Sofia & & & & & \\
\hline & & Carla & $\sqrt{2}$ & $\checkmark$ & $\checkmark$ & $x$ & $\checkmark 1$ \\
\hline \multirow{2}{*}{\multicolumn{2}{|c|}{$\begin{array}{c}\text { Relações } \\
\text { Intradisciplinares C-M }\end{array}$}} & Sofia & $x$ & $x$ & $x$ & $x$ & $x$ \\
\hline & & Carla & $\sqrt{2}$ & $\checkmark$ & $\checkmark$ & $x$ & $\checkmark_{1}$ \\
\hline \multirow{6}{*}{ 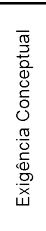 } & \multirow{2}{*}{$\begin{array}{c}\text { Relações } \\
\text { Intradisciplinares } \\
\text { C-C } \\
\end{array}$} & Sofia & $x$ & $x$ & $x$ & $x$ & $x$ \\
\hline & & Carla & $\sqrt{2}$ & $x$ & $x$ & $x$ & $x$ \\
\hline & \multirow{2}{*}{\begin{tabular}{|c|}
$\begin{array}{c}\text { Complexidade } \\
\text { das }\end{array}$ \\
Competências
\end{tabular}} & Sofia & $x$ & $x$ & $x$ & $x$ & $x$ \\
\hline & & Carla & $\sqrt{2}$ & $\checkmark$ & $x$ & $x$ & $x$ \\
\hline & \multirow{2}{*}{\begin{tabular}{|c|}
$\begin{array}{c}\text { Complexidade } \\
\text { dos } \\
\text { Conhecimentos }\end{array}$ \\
\end{tabular}} & Sofia & $x$ & $x$ & $x$ & $x$ & $x$ \\
\hline & & Carla & $x$ & $x$ & $x$ & $x$ & $x$ \\
\hline \multirow{2}{*}{\multicolumn{2}{|c|}{ Critérios de Avaliação }} & Sofia & $x$ & $x$ & $x$ & $x$ & $x$ \\
\hline & & Carla & $\sqrt{2}$ & $\checkmark$ & $\checkmark$ & $x$ & $\checkmark_{1}$ \\
\hline$\checkmark$ & Possui & $\checkmark_{1}$ & Possui Grau 1 & & $\sqrt{2}$ & Possui Grau 2 & \\
\hline$x$ & Não possui & & & & & & \\
\hline
\end{tabular}

A orientação específica de codificação da professora Carla varia, consoante as características em estudo. Para as características 'construção da ciência', 'relações intra-disciplinares entre conhecimentos científicos e metacientíficos' e 'critérios de avaliação', a professora Carla evidenciou a posse de regras de reconhecimento de nível elevado (Grau 2), a posse de regras de realização passiva e regras de realização ativa no nível mais baixo (Grau 1). No caso da 'construção da ciência', esta situação foi uma consequência da importância reconhecida por esta professora para a introdução da construção da ciência no processo de ensino-aprendizagem, assim como das razões/justificações dadas na entrevista (onde mostrou possuir regras de reconhecimento e de realização passiva). A professora Carla também conseguiu exemplificar como faria para introduzir as dimensões da ciência na sua prática, evidenciando regras de realização ativa ao nível da argumentação; contudo, foi incapaz de implementar os princípios que dissera valorizar (não possui regras de realização ativa ao nível da implementação). 
Quanto à situação de ausência de regras de realização ativa ao nível da implementação, no caso da Intradisciplinaridade C-M, é uma consequência do facto de a professora nunca ter estabelecido uma relação entre o conhecimento científico e metacientífico, em nenhuma das unidades de análise. Contudo, a professora Carla revelou ser capaz de estabelecer relações entre conhecimentos científicos e apelar a competências associadas às dimensões da ciência, algo que, apesar de válido, não é suficiente para uma eficaz aprendizagem científica. No que concerne aos critérios de avaliação, a professora Carla, nas aulas observadas, deixava implícitos, para os alunos, os aspetos relacionados com as características selecionadas no estudo sempre que essas características estavam presentes no seu processo de ensino-aprendizagem. A professora Carla usava, frequentemente, fichas de trabalho para orientar a aula e escrevia notas no quadro, de forma a enfatizar o texto legítimo por ela valorizado. Contudo, o texto com maior enfoque era limitado ao conhecimento científico e, dentro deste, a conhecimentos de nível conceptual baixo. Esta situação torna-se evidente quando se considera a característica 'complexidade dos conhecimentos científicos', onde a professora Carla não evidenciou regras de reconhecimento, regras de realização passiva nem regras de realização ativa ao nível da argumentação e da implementação.

Quanto à característica 'complexidade das competências científicas', a professora Carla evidenciou a posse de regras de reconhecimento de nível elevado (Grau 2), posse de regras de realização passiva e ausência de regras de realização ativa ao nível da argumentação e implementação. De facto, embora a professora tenha referido que valorizava a importância de um elevado nível de exigência conceptual das competências científicas e tenha procedido à devida justificação, nesse sentido, ela foi incapaz de exemplificar como faria para colocar em prática tais princípios na sua prática letiva e, naturalmente, não os conseguiu implementar. No que diz respeito à característica 'intradisciplinaridade entre diferentes conhecimentos científicos', esta professora evidenciou regras de reconhecimento de nível elevado, mas não mostrou possuir nem regras de realização passiva nem regras de realização ativa.

É de salientar que, analisando a OEC das professoras que participaram na investigação, se verificam diferenças evidentes ao nível das 
várias características de aprendizagem em estudo. Contudo, algo que é comum às duas professoras é a falta de regras de realização ativa ao nível da implementação, para todas as características. É, portanto, a parte da OEC das professoras que mais interfere com a aprendizagem dos alunos - a implementação dos princípios pedagógicos nas aulas lecionadas - aquela que mais lacunas apresenta.

\section{Conclusões}

Considerando a totalidade do estudo, a investigação sugere a existência de processos de recontextualização em dois níveis: dentro do campo de recontextualização oficial, quando se passa do documento geral do currículo para o dos princípios específicos do currículo; e entre o campo de recontextualização oficial e o campo de reprodução pedagógica, quando se passa do currículo para a prática pedagógica das professoras.

A análise dos princípios gerais do currículo (Competências Essenciais) mostrou, no geral, um nível muito baixo de conceptualização do conhecimento metacientífico e das competências associadas à construção da ciência, um nível de conceptualização elevado das competências científicas, um nível médio de conceptualização dos conhecimentos científicos, fracas relações intradisciplinares entre conhecimento científico e metacientífico, fortes relações intradisciplinares entre diferentes conhecimentos científicos, e critérios de avaliação implícitos quanto ao texto legítimo a ser transmitidoadquirido. Com exceção do nível de conceptualização das competências científicas e das relações intradisciplinares entre diferentes conhecimentos científicos, a secção geral do currículo contém características que, de acordo com investigações prévias (Morais, Neves, \& Pires, 2004; Morais \& Neves, 2009b), não promovem o desenvolvimento de uma efetiva aprendizagem científica.

A recontextualização que ocorreu entre os princípios gerais e os princípios específicos do currículo, em termos de aprendizagem científica, processou-se no sentido do reforço de características menos positivas, como é o caso dos critérios de avaliação implícitos, e no sentido do decréscimo da ênfase dado às características positivas (menor nível de conceptualização das competências e dos conhecimentos científicos). Estes processos de 
recontextualização são mais evidentes e extensíveis a outras características quando se considera a totalidade do currículo do $9^{\circ}$ ano de escolaridade (Calado \& Neves, 2012), e não apenas uma unidade temática, como foi o caso do presente estudo

As práticas pedagógicas das professoras mostraram diferenças, consoante as características pedagógicas em estudo, e a sua análise evidenciou processos de recontextualização do currículo que seguiram uma tendência similar ao processo verificado entre os dois documentos do currículo. Por exemplo, quando se considera a característica 'complexidade dos conhecimentos científicos', os dados mostraram que, apesar do nível de conceptualização relativamente elevado das Competências Essenciais, ambas as professoras valorizaram e implementaram um processo de ensinoaprendizagem com um nível baixo de conceptualização (mostraram não possuir regras de reconhecimento e regras de realização passiva e ativa para este microcontexto da aprendizagem científica).

No que diz respeito à característica 'complexidade das competências científicas', cujo nível de conceptualização era, também, elevado no documento Competências Essenciais do currículo, uma das professoras mostrou reconhecer e compreender a sua importância para a aprendizagem científica (possuía regras de reconhecimento e de realização passiva), mas nenhuma das professoras implementou tal princípio nas suas aulas (não possuíam regras de realização ativa).

Quanto às restantes características em estudo, as professoras mostraram-se incapazes de recontextualizar, nas suas práticas, os princípios do currículo no sentido de minimizar as características menos positivas do mesmo. Por exemplo, no que concerne às características 'construção da ciência', 'intradisciplinaridade entre conhecimentos científicos e metacientíficos', 'intradisciplinaridade entre diferentes conhecimentos científicos' e 'critérios de avaliação', ambas as professoras implementaram uma prática, ao nível da sala de aula, em que: o conhecimento metacientífico e a sua relação com o conhecimento científico estava ausente; o nível das relações intradisciplinares entre diferentes conhecimentos científicos era muito baixo; e os critérios de avaliação, quanto ao texto a ser aprendido pelos alunos, ficavam implícitos. Apesar disso, uma das professoras mostrou ter capacidade para reconhecer e compreender a importância, para a 
aprendizagem científica, da exploração de conhecimentos metacientíficos e da sua relação com os conhecimentos científicos, e também da explicitação dos critérios de avaliação quanto ao texto a ser apreendido pelos alunos (possuía regras de reconhecimento e de realização passiva). Essa professora era ainda capaz de reconhecer a importância de uma forte intradisciplinaridade entre diferentes conhecimentos científicos (possuía regras de reconhecimento).

O sentido dos processos de recontextualização verificados levanta sérias preocupações quanto à forma como os professores interpretam e implementam as direções curriculares, particularmente quando o currículo a ser implementado é desenvolvido num contexto de flexibilidade curricular. Visto que este contexto visa dar aos professores um maior espaço de intervenção ao nível da implementação do currículo, seria extremamente importante que os professores usassem esse espaço para melhorar os aspetos menos conseguidos na mensagem do currículo e desenvolvessem uma prática pedagógica em concordância com os resultados da investigação em educação em ciências. Pelo contrário, como é visível neste estudo, as professoras envolvidas na investigação usaram o seu espaço de intervenção para empobrecer, ainda mais, a mensagem presente nos documentos curriculares.

Seguindo o quadro conceptual que guiou a análise das práticas pedagógicas das professoras, é possível afirmar que um dos fatores responsáveis pela direção tomada na recontextualização do currículo é a ausência de regras de reconhecimento e/ou regras de realização passiva e/ou regras de realização ativa para as características em estudo. Esta ausência pode ser vista como uma consequência da formação de professores recebida, especialmente se tivermos em consideração a aquisição de orientação específica de codificação em termos de regras de reconhecimento e de realização passiva. No caso das regras de realização ativa, consideramos, também, que a formação de professores pode ter um papel decisivo na aquisição das mesmas. Contudo, pode-se também pensar, como hipótese, que as professoras do estudo poderiam ter falta de disposições socioafetivas favoráveis à implementação de uma prática pedagógica com as características em estudo. As dimensões pessoais, sociais e profissionais de um professor podem ter uma influência negativa no seu desempenho 
profissional. Estudos anteriores (Pires, 2001; Rosa, 2002) mostraram que certas características, tais como o compromisso, o dinamismo, a autoconfiança e as disposições socioafetivas, são determinantes para a implementação de uma determinada prática pedagógica.

As conclusões deste estudo são particularmente relevantes no âmbito do contexto de flexibilidade curricular que existe, atualmente, em Portugal. Se tivermos em consideração que a flexibilidade curricular, princípio base da presente reorganização curricular, pretende "assegurar que todos os alunos aprendam mais e de um modo mais significativo" (Departamento da Educação Básica, 1999, p. 6), então os resultados desta investigação deixam-nos certas dúvidas quanto à consecução desse propósito. A grande autonomia que está a ser dada aos professores, na sua relação com o Ministério da Educação, pode levar ao sucesso de apenas alguns alunos, visto que nem todos terão acesso a uma educação que promova níveis elevados de literacia científica. É, portanto, urgente a implementação de uma eficiente formação de professores e a promoção de um significativo desenvolvimento profissional para que, em contextos de maior autonomia pedagógica (e científica), os professores possam proceder a uma recontextualização do currículo na direção da promoção da literacia científica de todos os alunos.

Em termos metodológicos, o estudo assegura um passo em frente na investigação, através do aumento do rigor e da abrangência das linguagens externas de descrição anteriormente desenvolvidas para a análise das práticas pedagógicas dos professores e dos materiais curriculares (Castro, 2006; Morais, Neves, \& Afonso, 2005; Neves \& Morais, 2001b).

Deve ser enfatizado que as conclusões deste estudo não poderão ir no sentido de teorizar sobre processos de recontextualização desenvolvidos com base na análise das práticas de apenas duas professoras. Pretende-se, sim, suscitar questões quanto à formação dos professores e ao uso que os professores fazem do seu espaço de mudança, na promoção de uma melhor educação. O estudo tem limitações, não apenas no que concerne à reduzida amostra de professores, mas também no que diz respeito às características selecionadas para análise do currículo e da prática pedagógica, as quais deverão ser ampliadas em futuras investigações. 


\section{Agradecimentos}

As autoras agradecem a Isabel P. Neves pelas sugestões e à Fundação para a Ciência e Tecnologia (Programa FACC) pelo financiamento do estudo. Agradecem ainda à revista Pedagogies: An International Journal a autorização para utilizar texto de um artigo que nela foi anteriormente publicado

\section{Notas}

1 Ver instrumentos em Alves (2007). Também disponíveis em http://essa.fc.ul.pt/materiais_instrumentos_texto.htm\#2

2 Ver entrevista em Alves (2007).Também disponível em http://essa.fc.ul.pt/ficheiros/ instrumentos/4_formacao_de_professores/4.1.questionarios_entrevistas/ 4.1.10.pdf

3 Os instrumentos para a caracterização da prática pedagógica podem ser vistos em http://materiais_instrumentos_texto-htm\#2 e também em Alves (2007).

4 De forma a ampliar a linguagem externa de descrição e para uma melhor compreensão das várias dimensões da orientação específica de codificação, estabelecemos os níveis da argumentação e da implementação, dentro das regras de realização ativa.

5 A conceptualização deste instrumento foi baseada em Cantu e Herron, entre outros (Cantu \& Herron, 1978).

6 Outros dos indicadores do instrumento usado neste estudo são: solicitação das tarefas; questões/dúvidas dos alunos; e apresentação dos trabalhos/conclusão das atividades. Os indicadores selecionados referem-se a situações frequentes $\mathrm{e}$ relevantes numa sala de aula.

7 A conceptualização deste instrumento teve como base as ideias de Bloom (Bloom, Engelhart, Furst, Hill, \& Krathwohl, 1972).

8 Apesar de termos previsto que seria mais fácil, para o professor, dar a justificação correta na parte 2, de acordo com o modelo teórico, dado que já saberia, nessa fase, qual era a situação correta, nem sempre isso aconteceu. Os dados mostraram casos em que a parte 1 está em concordância com o modelo teórico e a parte 2 não está.

9 Resultados mais detalhados dos processos de recontextualização ocorridos podem ser vistos em Alves (2007). Os estudos desenvolvidos por Calado e Neves (2010) e Ferreira e Morais (2010), dentro do mesmo projeto de análise do Currículo Nacional de Ciências para o Ensino Básico, evidenciaram tendências similares.

\section{Referências}

Alves, V. (2007). O currículo, o software didáctico e a prática pedagógica: Análise sociológica de textos e contextos do ensino das ciências (Tese de Mestrado). Universidade Católica Portuguesa, Lisboa. 
Bernstein, B. (1990). Class, codes and control: Volume IV, The structuring of pedagogic discourse. Londres: Routledge.

Bernstein, B. (1996). Pedagogy, simbolic control and identity - Theory, research, critique. Londres: Taylor \& Francis.

Bernstein, B. (1999). Vertical and horizontal discourse: An essay. British Journal of Sociology of Education, 20(2), 157-173.

Bernstein, B. (2000). Pedagogy, symbolic control and identity - Theory, research, critique (ed. rev.). Londres: Rowman \& Littlefield.

Bloom, B., Engelhart, M., Furst, E., Hill, W., \& Krathwohl, D. (1972). Taxonomy of educational objectives: Cognitive domain. Nova lorque: David McKay Company, Inc.

Bogdan, R., \& Biklen, S. (1994). Investigação qualitativa em educação. Porto: Porto Editora.

Burkhardt, H., \& Schoenfeld, A. (2003). Improving educational research: Toward a more useful, more influential, and better-funded enterprise. Educational Researcher, 32(9), 3-14.

Calado, S., \& Neves, I. P. (2012). Currículo e manuais escolares em contexto de flexibilidade curricular - Estudo de processos de recontextualização. Revista Portuguesa de Educação, 25(1), 53-93.

Cantu, L., \& Herron, J. (1978). Concrete and formal Piagetian stages and science concept attainment. Journal of Research in Science Teaching, 15(2), 135-143.

Castro, S. (2006). A construção da ciência na educação científica do Ensino Secundário - Análise do novo programa de Biologia e Geologia do $10^{\circ}$ ano (Tese de Mestrado). Faculdade de Ciências, Universidade de Lisboa, Lisboa

Departamento da Educação Básica (1999). Gestão flexível do currículo. Lisboa: Ministério da Educação.

Domingos, A. M. (1989). Conceptual demand of science courses and social class. In P. Adey (Ed.), Adolescent development and school science (pp. 211-223). Londres: Falmer Press.

Ferreira, S., \& Morais, A. (2010). A natureza da ciência nos currículos de Ciências: Estudo do currículo de Ciências Naturais do $3^{\circ}$ Ciclo do Ensino Básico. Revista Portuguesa de Educação, 23(1), 119-156.

McComas, W. F., Clough, M. P., \& Almazroa, H. (1998). The role and character of the nature of science in science education. In W. F. McComas (Ed.), The nature of science in science education: Rationales and strategies (pp. 3-39). Holanda: Kluwer.

Morais, A. M. (2002). Basil Bernstein at the micro level of the classroom. British Journal of Sociology of Education, 23(4), 559-569.

Morais, A. M., \& Neves, I. (2001). Pedagogic social contexts: Studies for a sociological of learning. In A. Morais, I. Neves, B. Davies \& H. Daniels (Eds.), Towards a sociology of pedagogy: The contribution of Basil Bernstein to research (pp. 185221). Nova lorque: Peter Lang. 
Morais, A. M., \& Neves, I. P. (2005). Os professores como criadores de contextos sociais para a aprendizagem científica: Discussão de novas abordagens na formação de professores. Revista Portuguesa de Educação, 18(2), 153-183.

Morais, A. M., \& Neves, I. P. (2009). Textos e contextos educativos que promovem aprendizagem. Optimização de um modelo de prática pedagógica. Revista Portuguesa de Educação, 22(1), 5-28.

Morais, A. M., \& Neves, I. P. (2010). Basil Bernstein as an inspiration for educational research: Specific methodological approaches. In P. Singh, A. Sadovnik \& S. Semel (Eds.), Toolkits, translation devices, conceptual tyrannies: Essays on Basil Bernstein's sociology of knowledge. Nova lorque: Peter Lang.

Morais, A. M., Neves, I. P., \& Afonso, M. (2005). Teacher training processes and teachers' competence - A sociological study in the primary school. Teaching and Teacher Education, 21, 415-437.

Morais, A. M., Neves, I. P., \& Pires, D. (2004). The what and the how of teaching and learning: Going deeper into sociological analysis and intervention. In J. Muller, B. Davies \& A. Morais (Eds.), Reading Bernstein, researching Bernstein (Cap. 6). Londres: Routledge \& Falmer.

Neves, I. P., \& Morais, A. M. (2001a). Knowledges and values in science syllabuses: A sociological study of educational reforms. British Journal of Sociology of Education, 22(4), 531-556.

Neves, I. P., \& Morais, A. M. (2001b). Texts and contexts in educational systems: Studies of recontextualising spaces. In A. Morais, I. Neves, B. Davies \& H. Daniels (Eds.), Towards a sociology of pedagogy: The contribution of Basil Bernstein to research (pp. 223-249). Nova lorque: Peter Lang.

Neves, I. P., \& Morais, A. M. (2006). Processos de recontextualização num contexto de flexibilidade curricular - Análise da actual reforma das Ciências para o Ensino Básico. Revista de Educação, XIV(2), 75-94.

Pires, D. (2001). Práticas pedagógicas inovadoras em educação científica - Estudo no $1^{\circ}$ Ciclo do Ensino Básico (Tese de Mestrado). Faculdade de Ciências, Universidade de Lisboa, Lisboa.

Rosa, C. (2002). Actividades em ciências no jardim-de-infância: Estudo sobre o desenvolvimento profissional dos educadores (Tese de Mestrado). Faculdade de Ciências, Universidade de Lisboa, Lisboa.

Tashakkori, A., \& Creswell, J. W. (2007). The new era of mixed methods. Journal of Mixed Methods Research, 1(1), 3-7.

Vygotsky, L. (1978). Mind in society: The development of higher psychological processes. Cambridge, MA: Harvard University Press.

Ziman, J. (1984). An introduction to science studies - The philosophical and social aspects of science and technology. Cambridge: Cambridge University Press. 


\section{CURRICULUM AND PEDAGOGIC PRACTICES - A SOCIOLOGICAL ANALYSIS OF SCIENCE EDUCATION TEXTS AND CONTEXTS}

\section{Abstract}

The study analyses the extent to which the sociological message transmitted by the teachers' pedagogic practice recontextualizes the Official Pedagogic Discourse of the Natural Sciences curriculum for Portuguese middle school. Theoretically, the study is based on theories of psychology, epistemology and sociology, with a particular emphasis on Bernstein's theory of pedagogic discourse. A mixed methodology is used in the study. The results suggest the existence of processes of transformation of the message within the Ministry of Education, when passing from the general principles to the specific principles of the curriculum, in the direction of decreasing the quality of science education. The results of the curriculum analysis are discussed with regard to specific characteristics studied: metascientific knowledge, scientific knowledge and competences, intradisciplinary relations and evaluation criteria. The results also showed a decreasing of the quality of the teaching-learning process when passing from the curriculum to the pedagogic practices, shown by the absence, by teachers, of recognition and passive and active realization rules in most of the characteristics under study. These processes of transformation of the message are discussed, as well as its consequences in terms of scientific learning.

Keywords

Science education; Curriculum; Teaching practice; Recontextualization 


\title{
PROGRAMme ET PRACTICES PÉdAgogiques - UNE ANALYSE SOCIOLOGIQUE DES TEXTES ET CONTEXTES DE L'ÉDUCATION SCIENTIFIQUE
}

\begin{abstract}
Résumé
L'étude analyse dans quelle mesure le message sociologique transmis par le practice pédagogique des professeurs de Sciences Naturelles représente une recontextualisation du Discours Pédagogique Officiel véhiculé dans le programme de Sciences Naturelles de 3ème et 4ème. Théoriquement, la recherche présente des principes psychologiques, épistémologiques e sociologiques et est surtout basée dans la théorie du discours pédagogique de Bernstein. L'étude a utilisé une méthodologie mixte. Les résultats suggèrent l'existence de processus de transformation du message dans le Ministère de l'Éducation, quand on passe des principes générales du programme pour les principes spécifiques du même, dans le sens du baissement de la qualité scientifique. On discute les résultats du programme, à propos de caractéristiques particulaires étudiées: contenus métascientifiques, compétences et contenus scientifiques, intradisciplinarité et critères d'évaluation. Les résultats aussi montrent l'occurrence de une diminution de la qualité du processus d'enseignement-apprentissage, quand on passé du programme pour les practices pédagogiques, clair dans l'absence, par les professeurs, de la possession de règles de reconnaissance et réalisation passive et active pour la plupart des caractéristiques en étude. Ces processus de transformation du message sont discutés et sus conséquences, en termes de l'apprentissage scientifique, sont explorées.
\end{abstract}

Mots-clé

Éducation scientifique; Programmes; Practice pédagogique; Recontextualisation 